Aline Fernanda Bileski

Tatiana Comiotto

Jaison Vieira da Maia

\title{
Guia de sugestões para professores \\ Uma proposta de projetos investigativos em feiras de ciências
}

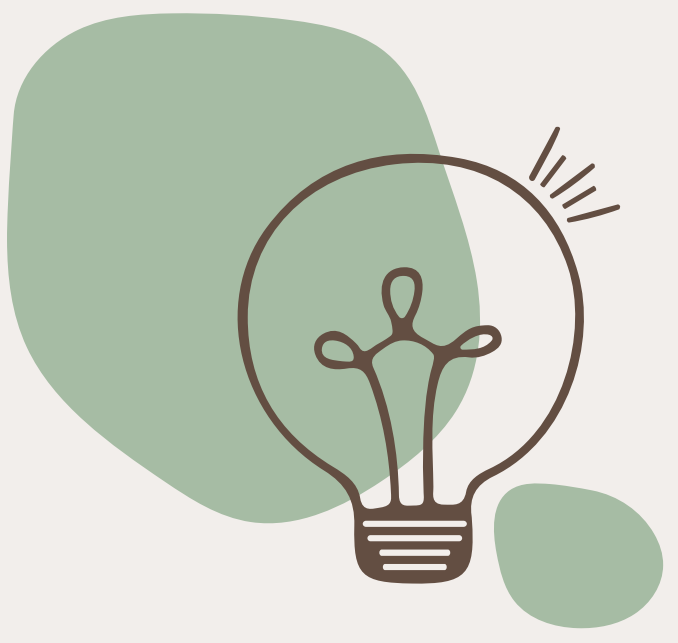

editora ufsc 


\section{Guia de sugestões para professores}


UNIVERSIDADE FEDERAL DE SANTA CATARINA

Reitor

Ubaldo Cesar Balthazar

Vice-Reitora

Catia Regina Silva de Carvalho Pinto

EDITORA DA UFSC

Diretora Executiva Interina

Flavia Vicenzi

Conselho Editorial

Agripa Faria Alexandre

Antonio de Pádua Carobrez

Carolina Fernandes da Silva

Evelyn Winter da Silva

Fábio Augusto Morales Soares

Fernando Luís Peixoto

Ione Ribeiro Valle

Jeferson de Lima Tomazelli

Josimari Telino de Lacerda

Luis Alberto Gómez

Marília de Nardin Budó

Núbia Carelli Pereira de Avelar

Priscila de Oliveira Moraes

Sandro Braga

Vanessa Aparecida Alves de Lima

Editora da UFSC

Campus Universitário - Trindade

88040-900 - Florianópolis-SC

Fone: (48) 3721-9408

editora@contato.ufsc.br

www.editora.ufsc.br 
Aline Fernanda Bileski

Tatiana Comiotto

Jaison Vieira da Maia

\title{
Guia de sugestões para professores
}

\author{
Uma proposta \\ de projetos investigativos \\ em feiras de ciências
}


() 2021 Editora da UFSC

Coordenação editorial:

Cristiano Tarouco

Capa:

Natalia Raposo

Editoração:

Cristiano Tarouco

Revisão:

Heloisa Hübbe de Miranda

Catalogação na fonte pela Biblioteca Universitária da Universidade Federal de Santa Catarina

B595g Bileski, Aline Fernanda

Guia de sugestões para professores [recurso eletrônico] : uma proposta de projetos investigativos em feiras de ciências / Aline Fernanda Bileski, Tatiana Comiotto, Jaison Vieira da Maia. Florianópolis : Editora da UFSC, 2021.

$72 \mathrm{p}$.

E-book (PDF)

Disponível em: https://doi.org/10.5007/978-65-5805-042-1

ISBN 978-65-5805-042-1

1. Ciência - Estudo e ensino. 2. Projetos científicos. 3. Ciência

- Experiências. 4. Pesquisa - Metodologia. 5. Prática de ensino.

I. Comiotto, Tatiana. II. Maia, Jaison Vieira da. III. Título.

CDU: $5 / 6: 37$

Ficha catalográfica elaborada por Fabrício Silva Assumpção - CRB-14/1673

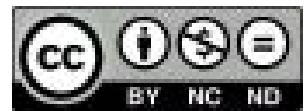

Este livro está sob a licença Creative Commons, que segue o princípio do acesso público à informação. O livro pode ser compartilhado desde que atribuídos os devidos créditos de autoria. Não é permitida nenhuma forma de alteração ou a sua utilização para fins comerciais.

br.creativecommons.org 


\section{Sumário}

Apresentação · 7

Capitulo 1

As feiras de ciências $\cdot 10$

Capítulo 2

Classificação de trabalhos em feiras de ciências 14

Capítulo 3

Características desejáveis na realização

dos trabalhos em feiras de ciências $\cdot 18$

\section{Capítulo 4}

Critérios de avaliação para os trabalhos

em feiras de ciências $\cdot 20$

\section{Capítulo 5}

O que são projetos investigativos? $\cdot 26$ 


\section{Capítulo 6}

Projetos investigativos: por onde começar? 31

\section{Capítulo 7}

Etapas da realização de projetos investigativos $\cdot 38$

Capítulo 8

Comunicando o projeto investigativo $\cdot 57$

\section{Capítulo 9}

Autoavaliação para os alunos e para o professor .59

Considerações finais $\cdot 64$

Apêndice $\cdot 65$

Sobre os autores $\cdot 72$ 


\section{Apresentação}

Este Guia foi desenvolvido a partir de um estudo realizado no contexto da XI Feira Estadual de Ciência e Tecnologia (FECITEC/ SC), realizada em Florianópolis-SC entre os dias 19 e 20 de outubro de 2016, e tem como finalidades apresentar sugestões e ser um material de apoio para professores da educação básica, com o intuito de que o utilizem como uma ferramenta para auxiliar seus alunos a realizarem projetos investigativos em sala de aula e após serem apresentados em feiras de ciências.

Optou-se em realizar projetos investigativos a partir da proposta de projetos de trabalho de Moura e Barbosa (2017), em que os alunos, ao realizarem projetos e pesquisas, estarão partindo de um problema que envolva um processo de aprendizagem vinculado ao seu cotidiano, abarcando diversas áreas do saber.

Essa proposta consiste em que os alunos realizem as investigações e sejam considerados como agentes ativos e participativos no processo da sua aprendizagem, e que o professor seja considerado como agente na mediação entre o educando e a busca por novos conhecimentos. 
Demo (2011) afirma que à medida que o aluno se torna um sujeito ativo, ele passa a questionar o conhecimento e a realidade, além de adquirir a independência crítica. $O$ referido autor denomina de questionamento reconstrutivo esse exercício constante de perguntar, de alimentar dúvidas, de perceber lacunas de conhecimento, que envolva a construção de argumentos consistentes, validados e aperfeiçoados a partir de uma crítica constante.

De acordo com Demo (2011), o professor deve propiciar uma educação autônoma e crítica, não cabe se limitar ao repasse de conteúdos, pois o desafio da sociedade do conhecimento é configurado pelo aprender a aprender. Além disso, o professor não consegue ensinar tudo ao seu aluno. Portanto precisa provocá-lo a acessar as informações em diferentes fontes, separá-las e selecionar quais são os conteúdos relevantes para responder ao questionamento proposto no decorrer do processo de aprendizagem. Esse processo visa o coletivo entre professor e aluno para que os dois trabalhem em parceria na busca das resoluções dos problemas escolares. Dessa forma o aluno participa do seu processo de ensino-aprendizagem tornando-se parceiro de trabalho do professor.

Com o objetivo de oferecer um caminho metodológico e prático para a realização de projetos investigativos, este Guia é composto por capítulos didático-pedagógicos que abordam conteúdos relacionados às feiras de ciências, de forma a permitir ao professor ter acesso à fundamentação teórica, às sugestões de atividades para propor aos alunos desenvolverem e, por último, às questões norteadoras para o professor avaliar as produções dos alunos, com o objetivo de melhor orientá-los durante a realização de projetos investigativos.

O Guia também conta com a ferramenta Lembre-se, professor!, em que são feitas sugestões com a proposta de desenvolver uma conversa com o leitor durante a orientação de projetos investigativos. Na ferramenta Para saber mais..., são indicadas algumas referências bibliográficas nas quais o professor pode buscar maior aprofundamento teórico. 
Após a etapa de finalização do projeto investigativo, o Guia apresenta para os alunos e para o professor uma proposta de autoavaliação, com o intuito de proporcionar-lhes uma visão crítica e reflexiva sobre o processo de ensino-aprendizagem em que foram envolvidos.

Todavia, o professor tem liberdade de adaptar as atividades como achar adequado, pois este Guia não se trata de um manual cuja estrita e acrítica obediência levará ao melhor resultado possível, mas pretende instigar o questionamento reconstrutivo oferecendo algumas discussões que poderão fazer com que o professor e os alunos reflitam sobre as suas produções.

\section{Referências}

DEMO, Pedro. Educar pela pesquisa. 9. ed. Campinas: Autores Associados, 2011.

MOURA, Dácio Guimarães; BARBOSA, Eduardo Fernandes.

Trabalhando com projetos: planejamento e gestão de projetos educacionais. Petrópolis: Vozes, 2017. E-book. 


\section{Capítulo 1 \\ As feiras de ciências}

De acordo com o Programa Nacional de Apoio a Feiras de Ciências (Fenaceb) 2006, atualmente as feiras de ciências são conhecidas como uma atividade pedagógica e cultural, com elevado potencial motivador do ensino e da prática científica no ambiente escolar. Tanto para alunos e professores quanto para a comunidade em geral, as feiras vêm constituindo uma oportunidade de aprendizagem e divulgação científica.

As feiras de ciências caracterizam-se como

[...] eventos que são realizados em escolas ou na comunidade com a intenção de, durante a exposição dos trabalhos, oportunizar diálogos com os visitantes e discussões acerca dos conhecimentos, das metodologias de pesquisa e da criatividade dos alunos envolvidos. (MANCUSO, 2000, p. 20). 
Corsini e Araújo (2007) consideram as feiras de ciências como espaços não formais de ensino. Já para os autores Simson, Park e Fernandes (2001), os espaços não formais de ensino não estão restritos ao limite da sala de aula, mas abertos a todas as possibilidades e interações, permitindo que os alunos aprendam através da prática, aplicando metodologias que possibilitem adquirir ou aprimorar seus conhecimentos de forma lúdica, criativa e participativa por meio do trabalho em grupo.

Os objetivos da realização das feiras de ciências consistem em:

Incentivar a atividade científica; favorecimento da realização de ações interdisciplinares; estimular o planejamento e execução de projetos; estimular o aluno na busca e elaboração de conclusões a partir de resultados obtidos por experimentação; desenvolver a capacidade do aluno na elaboração de critérios para compreensão de fenômenos ou fatos pertinentes a qualquer tipo, quer cotidiano, empírico ou científico; proporcionar aos alunos expositores uma experiência significativa no campo sociocientífico de difusão de conhecimentos; integração da escola com a comunidade. (PEREIRA; OAIGEN; HENNIG, 2000, p. 38).

Para Farias e Gonçalves (2007), esses eventos se constituem em espaços diferenciados de ensino-aprendizagem em relação a uma abordagem tradicional, no que se refere às relações professor, aluno e conhecimento, e também servem de formação e desenvolvimento de professores, proporcionando, por exemplo, debates e discussões sobre ensino-aprendizagem e o caráter investigativo dos trabalhos apresentados. Para Oaigen (2004), além de as feiras de ciências serem importantes momentos para a disseminação da produção científica, elas oportunizam a troca de experiências e conhecimentos, assim como despertam para a continuidade dos trabalhos e o aprofundamento teórico-prático das produções apresentadas. 
Pavão e Freitas (2008) afirmam que as feiras de ciências devem estar integradas ao currículo, sendo preparadas desde o início do período letivo para que o momento da apresentação seja o coroamento de todo um trabalho. Para Rosa (1995), eventos como esses consistem numa oportunidade de mostrar para a comunidade algo que já foi feito pelos alunos ao longo do ano letivo como reflexo dos trabalhos escolares em ciências. $\mathrm{O}$ referido autor ainda ressalta que as feiras devem ser realizadas porque existem trabalhos para serem mostrados e não o contrário, trabalhos a serem realizados porque vai haver uma feira.

É neste sentido que se entende o potencial e a importância das feiras de ciências, como espaços para troca de experiências, construção de conhecimentos e integração entre aluno, professor e a comunidade.

E você, professor, já participou de quantas feiras de ciências? A proposta dos eventos em que participou estava em consonância com o que foi exposto? E de que forma as feiras de ciências contribuíram para sua prática em sala de aula?

\section{Referências}

BRASIL. Ministério da Educação, Secretaria de Educação Básica. Programa Nacional de Apoio às Feiras de Ciências da Educação Básica Fenaceb. Brasília: MEC/SEB, 2006.

CORSINI, Aline Mendes do Amaral; ARAÚJO, Elaine Sandra Nicolini Nabuco de. Feira de ciências como espaço não formal de ensino: um estudo com alunos e professores do ensino fundamental. In: ENCONTRO NACIONAL DE PESQUISA EM EDUCAÇÃO EM CIÊNCIAS, 6., 2007. Anais [...]. Florianópolis: Associação Brasileira de Pesquisa em Educação em Ciências - ABRAPEC, 2007.

FARIAS, Luciana de Nazaré; GONÇALVES, Terezinha Valim Oliver. Feira de ciências como espaço de formação e desenvolvimento de professores e alunos. Amazônia - Revista de Educação em Ciências e Matemática, v. 3, n. 5, p. 25-33, jan.-jun. 2007.

MANCUSO, Ronaldo. Feiras de ciências: produção estudantil, avaliação, consequências. Contexto Educativo - revista digital de investigación y nuevas tecnologías, n. 6, abr. 2000. Disponível em: https://abre.ai/daNJ. Acesso em: 5 set. 2017. 
OAIGEN, Edson Roberto. A iniciação à educação científica e a compreensão dos fenômenos científicos: a função das atividades informais. In: ENCONTRO NACIONAL DE DIDÁTICA E PRÁTICA DE ENSINO (ENDIPE), 12., painel aberto, Curitiba, 2004. Anais [...]. Curitiba:

Champagnat, 2004. p. 2256-2277.

PAVÃO, Antonio Carlos; FREITAS, Denise (org.). Quanta ciência há no ensino de ciências. São Carlos-SP: EdUFSCar, 2008.

PEREIRA, Antônio Batista; OAIGEN, Edson Roberto; HENNIG, Georg. Feiras de ciências. Canoas-RS: Ulbra, 2000.

ROSA, Paulo Ricardo da Silva. Algumas questões relativas a feiras de ciências: para que servem e como devem ser organizadas. Caderno Brasileiro de Ensino de Física, Campo Grande-MS: UFMS, v. 12, n. 3, p. 223-228, 1995.

SIMSON, Olga R. de Moraes von; PARK, Margareth Brandini; FERNANDES, Renata Sieiro. Educação não formal: cenários da criação. Campinas-SP: Editora da Unicamp, Centro de Memória, 2001. 


\section{Capítulo 2 \\ Classificação de trabalhos em feiras de ciências}

Como visto no capítulo anterior, as feiras de ciências são espaços para incentivar a atividade científica buscando produzir conhecimentos, supostamente ainda não determinados. No entanto, entre os trabalhos apresentados em feiras de ciências predominam aqueles que consistem na reprodução do discurso presente em diferentes fontes de informação.

A partir da análise feita sobre os trabalhos apresentados na XI Feira Estadual de Ciência e Tecnologia da Educação Básica e Profissional do Estado de Santa Catarina (FECITEC/SC), realizada em Florianópolis-SC em 2016, foi definida uma classificação adaptada a partir de Mancuso (1993) e Moura (1995) para as produções apresentadas em feiras de ciências, conforme descrita a seguir. 
»Trabalhos representativos: consistem em ilustrar, aplicar, mostrar os princípios científicos de funcionamento de mecanismos e sistemas e/ou na apresentação de um protótipo sugerido para reprodução em maior escala.

»Trabalhos informativos: os alunos demonstram conhecimentos acadêmicos ou fazem alertas e/ou denúncias de conhecimentos julgados importantes à comunidade.

» Trabalhos construtivos: estão relacionados à construção de algo com objetivo de introduzir uma inovação, propor uma solução inusitada, apresentar algo com uma dimensão de inventividade, seja na função, seja na forma, seja no processo, seja na proposição de soluções e materiais alternativos, mas o seu desenvolvimento não segue o rigor científico.

»Projetos investigativos: voltados para projetos de pesquisa em torno de problemas e situações do cotidiano, visando sua maior compreensão e à indicação de possíveis soluções.

Para Farias (2005), os trabalhos representativos constituemse basicamente em uma extensão do modelo tradicional de ensino, pois os alunos se limitam a reproduzir o discurso presente em fontes como livros didáticos, internet, etc. De acordo com Santos e Schnetzler (2014), a realização desse tipo de trabalho consiste na reprodução de ideias, considera o conhecimento como algo pronto a ser transmitido aos alunos, e está limitada à concepção tradicional, em que os questionamentos dos alunos não são levados em consideração.

Em trabalhos informativos, os alunos visam divulgar, alertar/ denunciar conhecimentos julgados importantes à comunidade. Apesar de que nesse caso não predomina o exercício da pesquisa, Santos e Schnetzler (2014) afirmam que tal vinculação com uma problemática local possibilita tanto a elaboração de posicionamentos e tomada de decisões por parte dos sujeitos quanto ao encaminhamento de suas soluções. Dessa forma, em uma nova etapa, esse mesmo tema pode motivar um estudo mais aprofundado buscando novos conhecimentos acerca da problemática. 
Segundo Moura (1995), os trabalhos do tipo construtivos, que se referem à iniciativa de construir algo com a finalidade de introduzir alguma inovação durante o seu desenvolvimento, podem possibilitar que os alunos relacionem o conhecimento científico com o cotidiano. Dessa forma, é possível que em uma nova etapa esses trabalhos associem e reconstruam o conhecimento espontâneo em conhecimento científico, podendo assim, ao correlacioná-los, possibilitar que os alunos produzam novos conhecimentos.

Já o ensino com/por pesquisa difere da abordagem tradicional do conhecimento, valorizando a curiosidade dos alunos. De acordo com Moraes, Galiazzi e Ramos (2012), o processo de ensino com/ por pesquisa tem início com o ato de questionar/duvidar, sendo de fundamental importância que os próprios alunos estejam envolvidos na problematização de sua realidade, pois dessa forma a busca pelo conhecimento se tornará mais significativa para eles.

Apesar disso, Ulhôa et al. (2008) afirmam que projetos investigativos não são realizados pelos alunos devido à falta de apoio e de orientação docente, e também apontam para a necessidade de preparo e capacitação da escola, dos docentes e dos alunos para a realização desse tipo de produção.

Depois da leitura deste capítulo, você, professor, conseguiu identificar quais tipos de trabalho já orientou nas feiras de ciências das quais participou?

\section{Referências}

FARIAS, Luciana de Nazaré. Feiras de ciências como oportunidades de (re) construção do conhecimento pela pesquisa. 2005. 90 f. Dissertação (Mestrado em Educação em Ciências e Matemática) - Núcleo Pedagógico de Apoio ao Desenvolvimento, Universidade Federal do Pará, Belém, 2005.

MANCUSO, Ronaldo. A evolução do programa de feiras de ciências do Rio Grande do Sul: avaliação tradicional x avaliação participativa. 1993. $334 \mathrm{f}$. Dissertação (Mestrado em Educação) - Centro de Ciências da Educação, Universidade Federal de Santa Catarina, Florianópolis, 1993. 
MORAES, Roque; GALIAZZI; Maria do Carmo; RAMOS, Maurivan Güntzel. Pesquisa em sala de aula: fundamentos e pressupostos. In: MORAES, Roque; LIMA, Valderez Marina do Rosário (org.). Pesquisa em sala de aula: tendências para a educação em novos tempos. 3. ed. Porto Alegre: EDIPUCRS, 2012. p. 11-20.

MOURA, Dácio Guimarães. Feiras de ciências: necessidade de novas diretrizes. Presença Pedagógica, Belo Horizonte, n. 6, p. 15-20, nov.-dez. 1995.

SANTOS, Wildson Luiz Pereira dos; SCHNETZLER, Roseli Pacheco. Educação em química: compromisso com a cidadania. 4. ed. Ijuí: Editora Unijuí, 2014.

ULHÔA, Eliana et al. A formação do aluno pesquisador. Educação \& Tecnologia, [S.l.], v. 13, n. 2, fev. 2011. Disponível em: https://abre.ai/dhlD. Acesso em: 13 set. 2021. 


\section{Capítulo 3 \\ Características desejáveis na realização dos trabalhos em feiras de ciências}

Após a leitura dos capítulos anteriores, o professor leitor pode estar se perguntando neste momento: quais são as principais características para um trabalho realizado para feiras de ciências?

Rosa (1995) e Gonçalves (2008) apontam algumas características desejáveis para os trabalhos apresentados em eventos como as feiras de ciências.

Rosa (1995) recomenda que essas características sejam discutidas entre professores e alunos durante o planejamento da atividade:

»Caráter investigativo: é importante que o trabalho seja resultado de uma investigação realizada pelos alunos de um problema identificado no seu cotidiano e o que foi possível obter como resposta a alguma questão ou problema. 
»Criatividade: pode estar no uso de materiais, na temática ou no contexto investigado. Esse quesito procura responder às questões: o que esse trabalho tem de novo em relação ao que já foi produzido e/ou o que ele traz de novo para aquela comunidade em particular?

» Relevância: corresponde à importância do trabalho para a comunidade. É desejável que os trabalhos contribuam para mudanças sociais, ambientais ou tecnológicas na comunidade em que são investigados.

» Precisão científica: refere-se ao rigor à construção e ao tratamento das informações obtidas durante o estudo assim como à investigação, sendo que todos devem ser coerentes com o problema e os objetivos do trabalho.

Conforme a descrição dos referidos autores, é importante que sejam desenvolvidas investigações científicas partindo de um problema em busca de uma solução, e não mera reprodução de alguma atividade realizada em aula ou sugerida pelo professor orientador.

Agora já é possível responder ao questionamento inicial? Então, quais são as principais características para um trabalho realizado para feiras de ciências?

\section{Referências}

GONÇALVES, Terezinha Valin Oliver. Feiras de ciências e formação de professores. In: PAVÃO, Antônio Carlos; FREITAS, Denise de. Quanta ciência há no ensino de ciências. São Carlos: EdUFSCar, 2008. p. 207-216. ROSA, Paulo Ricardo da Silva. Algumas questões relativas a feiras de ciências: para que servem e como devem ser organizadas. Caderno Brasileiro Ensino de Física, Campo Grande-MS: UFMS, v. 12, n. 3, p. 223-228, 1995. 


\section{Capítulo 4 \\ Critérios de avaliação para os trabalhos em feiras de ciências}

O regulamento da XI FECITEC/SC estabeleceu alguns critérios gerais, para uma comissão julgadora avaliar os trabalhos enquanto estão sendo apresentados durante o evento. Neste capítulo serão apresentados esses critérios junto com a definição de cada um deles, baseados nos autores: Demo (2000), Alencar e Fleith (2003) e Marconi e Lakatos (2003).

\section{Metodologia científica ${ }^{1}$}

A metodologia científica traduz o processo por meio do qual o pesquisador pretende realizar sua investigação e obter seus resultados, 
relacionando o rigor da construção ao tratamento das informações obtidas durante o estudo e à investigação, possibilitando que os procedimentos desenvolvidos sejam repetidos, isto é, descreve o caminho propriamente dito. Baseado nos autores Marconi e Lakatos (2003, p. 84), são descritas algumas etapas que caracterizam uma investigação, sendo:

1) Formulação do problema: qualquer questão não resolvida e que é objeto de discussão em busca de uma solução, em qualquer domínio do conhecimento. O problema deve ser claro, preciso e objetivo, cuja solução seja viável pela pesquisa.

2) Levantamento bibliográfico: refere-se à contextualização teórica do problema e a sua relação com o objeto de investigação. Deve esclarecer portanto os pressupostos teóricos que fundamentam a pesquisa e as contribuições proporcionadas por investigações anteriores.

3) Instrumento de coleta de dados: é um conjunto de regras ou processos utilizados durante a coleta de dados, sendo que diferentes técnicas podem ser empregadas, cujas mais utilizadas são: a entrevista, o questionário, a observação, a experimentação e a pesquisa documental.

4) Coleta de dados: consiste no processo de levantamento dos dados necessários para a resolução do problema e na indicação de meios de atingir os objetivos propostos.

5) Tratamento dos dados: essa fase leva o pesquisador à teorização sobre os dados, produzindo o confronto entre a abordagem teórica anterior e o que a investigação de campo aporta de singular como contribuição.

6) Análise e discussão dos dados: tem como objetivo organizar e sintetizar os dados de tal forma que possibilitem o fornecimento de respostas ao problema proposto para investigação. 


\section{Conhecimento científico do problema abordado}

De acordo com Demo (2000, p. 26-29), para que o discurso possa ser reconhecido como científico precisa ser lógico, sistemático, coerente, sobretudo bem argumentado, isto é o que o diferencia de outros conhecimentos, como senso comum, sabedoria e ideologia. Sobre os critérios formais de demarcação científica, tem-se:

1) Coerência: critério mais propriamente lógico e formal, significando a ausência de contradição no texto, fluência entre premissas e conclusões, deve ser desenvolvido amarrando bem as ideias, chegando às conclusões sem dificuldades. Trata-se de um procedimento importante pelo exercício da lógica formal e pela habilidade de uso sistemático de conceitos e teorias.

2) Sistematicidade: caminha junto com a coerência, significa o esforço de dar conta do tema em sua amplitude sem que se esgote, porque nenhum tema é esgotável, incluindo nisso, que o texto seja enxuto, direto, claro, feito para ser entendido na primeira leitura.

3) Consistência: refere-se à capacidade do texto de resistir ao contra-argumento, ou seja, permitir opiniões contrárias, pois fazer ciência é saber argumentar não só como técnica de domínio lógico, mas sobretudo como arte reconstrutiva. Saber argumentar é saber pesquisar, juntando tudo que está sendo estudado para elaboração própria, para explicar o como das coisas, alegar razões, apresentar os porquês. Para afirmar algo, o texto precisa ter base, primeiro no conhecimento existente e considerado válido e só depois na formulação própria do autor.

4) Originalidade: refere-se à expectativa de encontrar inovação no discurso científico. Para que seja algo novo, no sentido reconstrutivo, busca-se outro nível por meio de análises profundas de autores e teorias, confrontando-as com rigor, para que, a partir daí, seja possível alguma formulação própria. 
5) Objetivação: seria um processo de construção do objeto da pesquisa que reconhece sua complexidade e sua especificidade referindo-se ao esforço de tratar a realidade assim como ela é, possuir o compromisso metodológico de dar conta da realidade da maneira mais próxima possível. Vale a regra: tudo que fazemos em ciência deve poder ser refeito por quem dela duvide. Daí se assegura que não é somente o que tem base empírica que tem validade, e que as teorias necessitam ser referenciadas a realidades que permitam relativo controle do que se diz.

6) Discutibilidade: questionamento com coerência, dentro do princípio metodológico de que a coerência da crítica está na autocrítica. Conhecimento científico busca fundamentar-se de todos os modos possíveis, mas tem consciência crítica de que alcança esse objetivo apenas parcialmente pela tessitura própria do discurso científico.

\section{Criatividade}

Inicialmente para uma investigação ser criativa e inovadora, ela deve buscar propor uma resposta original à questão levantada. Além disso, deve apresentar um método eficiente e confiável de resolver o problema. De acordo com Alencar e Fleith (2003), o ato criativo pode ser gerado a partir da identificação da necessidade de resolução de problemas, da constatação de deficiências, da existência de lacunas no conhecimento, de desarmonias, de dificuldades, de incongruências, entre outras.

Os referidos autores identificam duas dimensões que parecem permear a noção de criatividade:

Pode-se notar que uma das principais dimensões presente nas mais diversas definições de criatividade diz respeito ao fato de que criatividade implica na emergência de um produto novo, seja uma ideia ou invenção original, seja a reelaboração e aperfeiçoamento de produtos ou ideias já existentes. Também presente em muitas das definições propostas é o fator de 
relevância, ou seja, não basta que a resposta seja nova; é também necessário que seja apropriada a uma dada situação. (ALENCAR; FLEITH, 2003, p. 15).

Para Demo (2000), a investigação científica visa à produção de conhecimento novo. No início tende a aproveitar os saberes e conhecimentos de outros autores, após, com o exercício contínuo da investigação científica, se consolida a autoria, a criatividade e a originalidade da produção de conhecimentos, bem como a síntese de novos saberes.

\section{Clareza e objetividade na apresentação do trabalho}

Durante a apresentação do trabalho é importante que se consiga passar confiança e clareza àqueles que assistem para que o trabalho tenha maior credibilidade. Para isso é essencial que seja elaborado adequadamente um pôster assim como fazer uma boa apresentação oral e corporal.

O pôster deve apresentar de forma sucinta os objetivos, $\mathrm{O}$ desenvolvimento, os resultados e as conclusões do trabalho, sendo que as informações devem estar organizadas de forma coerente e atrativa. A apresentação oral também deve ser organizada e coerente, demonstrando compreensão real sobre o conteúdo abordado, ou seja, a comunicação do trabalho não deve consistir numa apresentação decorada (FEBRACE, 2010).

Feita uma relação entre os critérios de avaliação da FECITEC/ SC com outros eventos de Iniciação Científica percebe-se que são muito similares. No entanto, vale ressaltar que o uso do referido regulamento é um exemplo. Dessa forma, tendo interesse em participar de determinado evento, sugere-se que o professor busque ler o regulamento antes de iniciar a orientação de trabalhos, buscando maior direcionamento na sua elaboração e realização.

Dos eventos de Iniciação Científica que o professor já participou, quais foram os pontos do regulamento que mais chamaram a sua atenção? 
No capítulo 7, o professor vai encontrar questões norteadoras que visam auxiliá-lo na avaliação das produções dos alunos, com o objetivo de orientá-los durante a realização de projetos investigativos.

\section{Referências}

ALENCAR, Eunice M. L. Soriano de; FLEITH, Denise de S. Criatividade: múltiplas perspectivas. Brasília: Editora UnB, 2003.

DEMO, Pedro. Metodologia do conhecimento científico. São Paulo: Atlas, 2000.

FEBRACE. Manual do avaliador. Disponível em: https://abre.ai/daNL.

Acesso em: 20 out. 2017.

MARCONI, Marina de Andrade; LAKATOS, Eva Maria. Fundamentos de metodologia científica. 5. ed. São Paulo: Atlas, 2003. 


\section{Capítulo 5}

\section{O que são projetos investigativos?}

A abordagem de projetos investigativos está voltada para projetos de pesquisa em torno de problemas e situações do cotidiano, visando sua maior compreensão e a indicação de possíveis soluções, contemplando uma relação diferente com o conteúdo:

Em vez de partir dele, como no modelo tradicional, transmissor e informativo, parte-se de um desafio, o qual, para ser resolvido, exige a incorporação de novos conteúdos pelos alunos. Estes saem da posição de "sujeitos ditos passivos" e se colocam como sujeitos que querem participar, criar, modificar. E o professor também transita do transmissor, centralizador, para o facilitador ou mediador da aprendizagem, partindo do princípio de que mediar é negociar, equilibrar, ajustar. (OLIVEIRA, 2006, p. 14, grifo do autor). 
Na proposta apresentada neste Guia, projetos investigativos serão desenvolvidos através de projetos de trabalho, uma metodologia apontada como instrumento para a melhoria do processo educativo, promovendo a aprendizagem significativa como contraponto à aprendizagem tradicional, teórica e descontextualizada.

Os projetos são verdadeiras fontes de investigação e criação, passando por processos de pesquisas, aprofundamento, análise, depuração, criação de novas hipóteses, instigando, a todo momento, as diferentes potencialidades dos elementos do grupo, bem como as suas limitações. (NOGUEIRA, 2007, p. 80).

Dentre as diferentes propostas de projetos de trabalhos, optou-se pela proposta adotada por Moura e Barbosa (2017). Os referidos autores indicam aos alunos que ao realizarem projetos e pesquisas devem partir de um problema que envolva um processo de aprendizagem vinculado ao seu cotidiano, abarcando diversas áreas do saber.

Dessa forma, ao desenvolverem projetos de trabalho, os alunos estarão desenvolvendo ao mesmo tempo conhecimentos e habilidades que são comuns às atividades de desenvolvimento de projetos e de pesquisas. Na proposta dos referidos autores:

Os projetos são desenvolvidos por alunos em uma (ou mais) disciplina(s), no contexto escolar, sob a orientação do professor, e têm por objetivo a aprendizagem de conceitos e o desenvolvimento de competências e habilidades específicas. Esses projetos são conduzidos de acordo com uma metodologia denominada Metodologia de Projetos, ou Pedagogia de Projetos. [...] os projetos de trabalho são executados pelos alunos sob a orientação do professor visando a aquisição de determinados conhecimentos, habilidades e valores. (MOURA; BARBOSA, 2017, p. 28). 
Para Moura e Barbosa, um projeto pode ser visto como um empreendimento que propõe produzir algo novo. A pesquisa, por sua vez, tem como finalidade a promoção do conhecimento. Dessa forma, eles atestam que toda pesquisa é um projeto pois produz algo novo, nesse caso um conhecimento, e assim definem projetos de pesquisa como "projetos que têm por objetivo a obtenção de conhecimentos sobre determinado problema, questão ou assunto" (MOURA; BARBOSA, 2017, p. 29).

Moura, Barbosa e Moreira (2008) afirmam que as pesquisas realizadas pelos alunos devem ser estruturadas com o objetivo principal de produzir conhecimentos supostamente ainda não determinados. No entanto, não é necessária a produção de conhecimentos novos para o mundo da ciência, podendo haver construção de um conhecimento novo para o aluno. Portilho e Almeida (2008) chamam a pesquisa do aluno de pesquisa escolar. Para esses autores, a pesquisa escolar é sem dúvida:

Um relevante instrumento metodológico de ensino-aprendizagem, sendo que, através dela é possível desenvolver ações que levem à interdisciplinaridade, palavra de ordem no atual contexto educacional. Sua utilização induz ao desenvolvimento de competências e habilidades indispensáveis à formação do educando. Sua prática permite que o aluno aprenda ao transformar informação em conhecimento. (PORTILHO; ALMEIDA, 2008, p. 19).

Cacilda Oliveira afirma que os projetos de trabalho são baseados na problematização. $\mathrm{O}$ aluno deve ser envolvido no problema, cabendo a ele "investigar, registrar dados, formular hipóteses, tomar decisões, resolver o problema, tornando-se sujeito de seu próprio conhecimento" (OLIVEIRA, 2006, p. 13). A referida autora ainda acrescenta que o professor deixa de ser o único responsável pela aprendizagem do aluno e torna-se um pesquisador, o orientador do interesse de seus alunos, pois

[...] levanta questões e se torna um parceiro na procura de soluções dos problemas, gerencia todo o processo de desen- 
volvimento do projeto, coordena os conhecimentos específicos de sua área de formação com as necessidades dos alunos de construir conhecimentos específicos. (OLIVEIRA, 2006, p. 13).

Segundo Ribeiro (2005), ao vivenciar o ambiente proporcionado pela pesquisa, nesse caso, no desenvolvimento de projetos investigativos, os participantes adquirem mais confiança em suas decisões e na aplicação do conhecimento em situações práticas, melhoram as relações interpessoais, aprendem a se expressar de forma oral e escrita, adquirem o gosto pela pesquisa e pela resolução de problemas, além de terem a oportunidade de experimentar situações que demandam as tomadas de decisões, reforçando a autonomia no pensar e no agir.

Para Schiel (2005), o professor deve promover a investigação, a experimentação e o discurso, em vez de apenas repassar conteúdos. No entanto, a proposta não é formar cientistas, mas possibilitar que o aluno se aproprie de uma metodologia científica, compreendendo como ocorre a construção de conhecimentos e das ciências, possibilitando a visão de ciências como uma interpretação do mundo, ampliando as habilidades relacionadas à aprendizagem e não como um conjunto de respostas prontas e definitivas.

Na opinião do professor, é possível fazer ciência na sala de aula? Qual o seu interesse em orientar projetos investigativos?

\section{Referências}

MOURA, Dácio Guimarães; BARBOSA, Eduardo Fernandes.

Trabalhando com projetos: planejamento e gestão de projetos educacionais. Petrópolis: Vozes, 2017. E-book.

MOURA, Dácio Guimarães; BARBOSA, Eduardo Fernandes; MOREIRA, Adelson F. Iniciação Científica na Educação Básica: níveis de engajamento, o aluno pesquisador e concepção de egressos sobre o trabalho. In: ENCONTRO NACIONAL DE DIDÁTICA E PRÁTICA DE ENSINO, 15., 2010, Belo Horizonte. Anais [...] Universidade Federal de Minas Gerais, Belo Horizonte, 20-23 abr. 2010. 
NOGUEIRA, Nilbo Ribeiro. Pedagogia dos projetos: uma jornada interdisciplinar rumo ao desenvolvimento das múltiplas inteligências. São Paulo: Érica, 2007.

OLIVEIRA, Cacilda Lages. Significado e contribuições da afetividade, no contexto da Metodologia de Projetos na Educação Básica. 2006.

Dissertação (Mestrado em Educação Tecnológica) - Centro Federal de Educação Tecnológica de Minas Gerais, Belo Horizonte, 2006. Capítulo 2. Disponível em: https://abre.ai/djQC. Acesso em: 2 out. 2017.

PORTILHO, Evelise Maria Labatut; ALMEIDA, Siderly do Carmo Dahle de. Avaliando a aprendizagem e o ensino com pesquisa no Ensino Médio. Ensaio: Avaliação e Políticas Públicas em Educação, Rio de Janeiro, v. 16, n. 60, jul.-set. 2008.

RIBEIRO, Luis Roberto de Camargo. A aprendizagem baseada em problemas (PBL): uma implementação na educação em engenharia na voz dos atores. 2005. 236 f. Tese (Doutorado em Ciências Humanas) Universidade Federal de São Carlos, São Carlos-SP, 2005.

SCHIEL, Dietrich (org.). Ensinar as ciências na escola. São Carlos-SP: CDCC/USP, 2005. 


\section{Capítulo 6 \\ Projetos investigativos: por onde começar?}

Este capítulo é dividido em tópicos que tratam sobre como iniciar um projeto investigativo. Entre os tópicos estão: o papel do professor, como incentivar seus alunos a realizarem projetos investigativos, sugestão para o levantamento de ideias, formação de grupos de pesquisa e escolha dos temas e a importância de registros no diário de bordo.

\section{O papel do professor}

Neste tópico será discutido de um modo geral o papel do professor durante a realização de projetos investigativos em sala de aula. Além disso, também se pretende destacar o papel do professor nas etapas da realização do trabalho, através do ícone Lembre-se, professor! com objetivo de desenvolver uma conversa com o leitor durante a orientação de projetos investigativos. 
O professor, ao optar em realizar projetos investigativos na sala de aula, visa a parceria entre professor e aluno para que os dois trabalhem na busca das resoluções dos problemas. Dessa forma o aluno estará mais envolvido no processo de ensino-aprendizagem, além de tornar-se parceiro de trabalho do professor.

Assim o professor assume um papel fundamental, atuando como um orientador, ou seja, facilitador da aprendizagem do aluno, ajudando-o a resolver problemas, criando condições para que ele próprio resolva novas situações que lhe for apresentadas, permitindo que o aluno seja protagonista do seu próprio conhecimento.

É importante que já no início do ano letivo o professor tenha definido os assuntos que serão trabalhados no decorrer desse período, para que consiga culminar esses assuntos com os projetos investigativos que serão realizados.

Segundo Machado (2000), o professor deve tomar cuidado para que diante das dificuldades dos alunos, de forma entusiasmada, não determine as metas a serem atingidas. Para o autor, os projetos devem ser realizados conjuntamente, e é importante que o professor incentive os alunos a trabalharem em grupo, ressaltando a importância de todos os envolvidos no projeto compreenderem e concordarem com cada proposição.

Professor, uma sugestão é que inicialmente oriente seus alunos a realizarem projetos com um pequeno nível de complexidade, e numa próxima experiência, isto é, no próximo projeto investigativo a ser realizado, desafie seus alunos a realizarem investigações um pouco mais complexas.

Por último, ressalta-se que você, professor, preocupe-se mais com o processo do que com o produto final, ou seja, o objetivo maior é que o aluno compreenda como ocorre a construção de conhecimentos e das ciências, possibilitando a visão de ciências como uma interpretação do mundo, ampliando as habilidades relacionadas à aprendizagem e não como um conjunto de respostas prontas e definitivas. 


\section{Como você, professor, pode incentivar seus alunos a realizarem projetos investigativos?}

Professor, como você sabe, seus alunos podem não estar habituados a realizar projetos investigativos durante as aulas. Nesse sentido, sugere-se que o professor realize com seus alunos a atividade "Quem faz ciência?".

Adaptada de Burger (2013), a atividade tem como objetivo refletir, discutir sobre quem faz ciência e demonstrar aos alunos que fazer ciência não está restrito somente aos gênios e ao espaço laboratorial. Assim o professor pode encorajar seus alunos a fazer ciência na sala de aula.

Para a realização dessa atividade, a turma se reunirá em pequenos grupos, formados por três ou quatro integrantes. Após, o professor entregará a cada grupo uma folha sulfite A4, e levantará alguns questionamentos para a turma, por exemplo: Quem faz ciência? Quais suas características? Em seguida, os grupos discutirão e irão representar suas respostas em forma de desenhos, o resultado das discussões será socializado posteriormente com o restante da turma.

Pavão e Freitas (2008, p. 12) consideram que "fazer ciência na escola é utilizar procedimentos próprios da ciência como observar, formular hipóteses, experimentar, registrar, sistematizar, analisar, etc.".

É importante que o professor também discuta sobre as características de um cientista. Por exemplo, um cientista deve ser curioso, observador e ter uma postura honesta, crítica e objetiva sobre o que irá pesquisar. Também deve agir com imparcialidade e credibilidade, desenvolvendo pesquisas precisas e comprováveis, de maneira a produzir conhecimento confiável, ampliando e contribuindo para o saber científico.

\section{Levantamento de ideias e formação de grupos de pesquisa}

Neste item serão apresentadas sugestões para o levantamento de ideias e para a formação dos grupos de pesquisa. De maneira dinâmica, o professor pode buscar explorar as ideias dos alunos e incentivá-los 
a realizar projetos investigativos sobre temas de seus próprios interesses. De acordo com Moura e Barbosa (2017), os projetos nascem a partir de problemas, necessidades, oportunidades e desafios identificados.

Inicialmente, professor, desenvolva uma reflexão, a partir de questionamentos tais como:

»O que aprendemos e o que já sabemos, no momento, sobre os assuntos que estamos estudando? Que curiosidades identificamos a partir das atividades desencadeadoras e das atividades derivadas que estamos realizando?

»Que dúvidas estão surgindo sobre os assuntos que estamos trabalhando?

O professor também pode orientar seus alunos a observarem seu ambiente, a escola, o bairro, a cidade. O objetivo é fazer com que os alunos consigam identificar curiosidades e dúvidas, e que a partir delas deem início à organização dos projetos investigativos.

Numa aula seguinte, sugere-se que os levantamentos das dúvidas e curiosidades sejam feitos no quadro, de forma que fique fácil para todos acompanharem as contribuições individuais. É fundamental que todos os alunos consigam construir uma ideia do conjunto das aprendizagens, curiosidades e dúvidas levantadas a partir dos temas que estão estudando nas atividades desencadeadoras e nas derivadas.

Após todos exporem suas ideias, os grupos de pesquisas serão formados. Os alunos podem optar em trabalhar individualmente ou em grupos formados por quatro integrantes, no máximo, pois, conforme Behrens (2015), se o grupo for muito numeroso pode comprometer a qualidade da aprendizagem. Também seria interessante que os alunos se reunissem de acordo com os mesmos interesses e curiosidades, e não que os agrupamentos fossem por afinidades pessoais.

Veiga (2000) afirma que no trabalho em grupo os alunos não só aprenderão com o professor, mas também com os colegas, através da troca de experiências e informações, criando situações que favoreçam o desenvolvimento da sociabilidade, da cooperação e do respeito mútuo, além de permitir maior avanço na organização do pensamento do que se cada indivíduo estivesse só. 
Antes de iniciar os projetos investigativos, professor, apresente aos seus alunos trabalhos desenvolvidos dentro dessa mesma proposta. Você pode encontrar projetos investigativos desenvolvidos por alunos da educação básica em diferentes periódicos. Seguem algumas sugestões.

Para saber mais...

Estas referências apresentam investigações científicas, isto é, projetos investigativos desenvolvidos por alunos da educação básica:

FEBRACE. FEBRACE virtual. Disponível em: https://abre.ai/c6NM. Acesso em: 23 dez. 2017.

IFSC. Conectando saberes. Disponível em: https://abre.ai/c6NN. Acesso em: 23 dez. 2017.

\section{A escolha do tema}

O tema é o assunto que se deseja pesquisar. Pode surgir de curiosidades, problemas, necessidades, oportunidades e desafios identificados no ambiente, seja a escola, o bairro, a cidade.

Com os grupos de pesquisa já formados, é o momento de decidir o tema do projeto. Em projetos investigativos, quem escolhe o tema a ser investigado são os alunos em conjunto com o professor.

Lembre-se, professor!

O trabalho a ser realizado deve estar adequado ao currículo, ou seja, deve refletir o tipo de assunto estudado em sala de aula. Cabe ao professor incentivar o pensamento crítico do aluno, não oferecendo apenas respostas, mas levantando perguntas em conjunto, discutindo sobre o tema do projeto e indicando oportunidades que o aluno desconheça.

\section{O diário de bordo}

O diário de bordo é um caderno (ou pasta) no qual os alunos registram as etapas que realizam no desenvolvimento do projeto. 
Sugere-se ao professor que oriente seus alunos a organizarem um diário de bordo, ressaltando a sua importância. Para isso alguns questionamentos podem ser utilizados, como:

»Quando realizamos um experimento, por que devemos fazer anotações?

»Qual o lugar mais adequado para realizar as anotações?

»O que deve ser anotado?

Após, o professor pode indicar aos alunos algumas referências sobre o uso do diário de bordo (podem ser utilizadas as mesmas indicadas no Para saber mais...). Depois dos grupos realizarem seus primeiros registros, seria interessante o professor analisar e verificar o que pode ser melhorado, visando contribuir para melhores registros.

Lembre-se, professor!

Quem faz os registros no diário de bordo são os alunos. Costuma-se utilizar uma linguagem mais informal. $O$ diário é um instrumento de acompanhamento do trabalho sendo realizado. O professor pode usá-lo para verificar o que está sendo feito, orientar o grupo e avaliar o andamento do projeto e dos próprios alunos.

Para saber mais...

As referências abaixo discutem sobre o diário de bordo:

CARNEIRO, Mára Lúcia Fernandes; GELLER, Marlise; PASSERINO, Liliana. Navegando em ambientes virtuais: metodologias e estratégias para o novo aluno. Disponível em: https://abre.ai/c6RF. Acesso em: 13 set. 2021.

FEBRACE. O que é o diário de bordo? Disponível em: https://abre.ai/ daNO. Acesso em: 15 out. 2017.

MONTEIRO, Manuela Matos. Área de projecto: guia do aluno - $12^{\circ}$ ano. Porto: Porto Editora, 2007. Disponível em: https://abre.ai/c6RI. Acesso em: 15 out. 2017. 


\section{Referências}

BEHRENS, Marilda Aparecida. Metodologia de projetos: aprender e ensinar para a produção do conhecimento numa visão complexa. In: TORRES, Patrícia Lupion (org.). Metodologias para a produção do conhecimento: da concepção à prática. Curitiba: SENAR-PR, 2015. p. 97-116.

BURGER, Jussara Tainá. Alfabetização científica e redes sociais: um estudo exploratório a partir de uma intervenção pedagógica no ensino de física. 2013. 99 f. Trabalho de Conclusão de Curso (Graduação em Licenciatura em Ciências da Natureza) - Instituto Federal de Educação, Ciência e Tecnologia de Santa Catarina, Jaraguá do Sul, 2013. Disponível em: https:// abre.ai/djQD. Acesso em: jan. 2021.

MACHADO, Nilson José. Educação: projetos e valores. São Paulo: Escrituras, 2000.

MOURA, Dácio Guimarães; BARBOSA, Eduardo Fernandes.

Trabalhando com projetos: planejamento e gestão de projetos educacionais. Petrópolis: Vozes, 2017. E-book.

PAVÃO, Antônio Carlos; FREITAS, Denise de. Quanta ciência há no ensino de ciências. São Carlos: EdUFSCar, 2008.

VEIGA, Ilma Passos Alencastro. O seminário como técnica de ensino socializado. In: VEIGA, Ilma Passos Alencastro (org.). Técnicas de ensino: por que não? Campinas: Papirus, 2000. 


\section{Capítulo 7 \\ Etapas da realização de projetos investigativos}

Adaptado de Moura e Barbosa (2017), para a realização de projetos investigativos foram definidas as seguintes etapas, conforme demonstrado na figura abaixo.

Figura 7.1 - Etapas para a realização de projetos investigativos

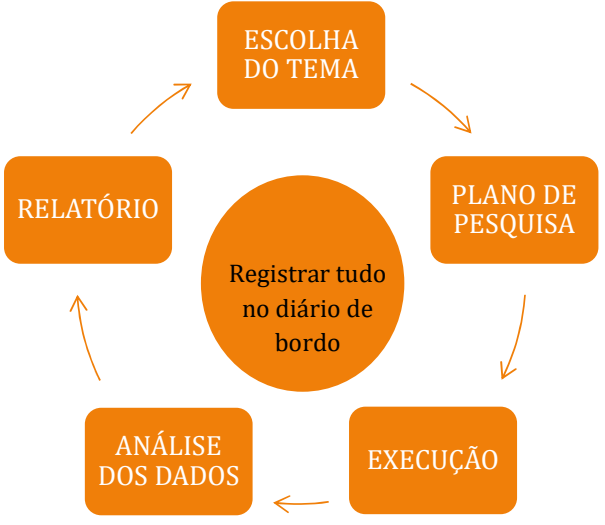

Fonte: Adaptado de Moura e Barbosa (2017). 
O plano de pesquisa, como o nome já diz, é um planejamento inicial da pesquisa, como uma prévia do que será feito e, portanto, deve ser preparado antes que a pesquisa seja iniciada. Existem diferentes modelos de plano de pesquisa. Aqui será apresentada uma sugestão contendo os itens conforme a figura abaixo:

Figura 7.2 - Elementos do plano de pesquisa

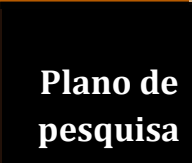

\section{- Problema - O que vai ser investigado?}

\section{Justificativa - Por que investigar?}

- Hipóteses - Quais as possíveis respostas para o problema?

\section{- Objetivos - Para que investigar?}

- Revisão bibliográfica - O que já foi investigado sobre o tema?

- Metodologia - Como investigar?

- Cronograma - Quando investigar?

- Recursos - Com o que investigar?

- Etapas relacionadas ao escopo da pesquisa.

Fonte: Adaptado de Moura e Barbosa (2017).

\section{Problema - O que vai ser investigado?}

Após a escolha do tema, é preciso deixar claro sobre o que se pretende investigar, isto é, elaborar um problema de pesquisa. Os problemas pertinentes ao tema surgirão da reflexão coletiva entre o professor e os alunos.

Segundo Rosa (1995, p. 225), "os trabalhos realizados para as feiras de ciências devem estar adequados ao currículo, ou seja, o trabalho a ser apresentado na feira deve refletir sobre o tipo de assunto estudado na sala de aula". 
Lembre-se, professor!

Nesse momento o professor deve estar atento em adequar o trabalho a ser realizado ao currículo, isto é, verificar quais os assuntos trabalhados em sala de aula. Assuntos das demais disciplinas poderão ser acrescentados ao projeto investigativo que será realizado.

O problema deve ser elaborado em forma de interrogação e deve contribuir para o conhecimento de algo que não se sabe. Não precisa necessariamente ser inédito, pode ser algo sobre um assunto já pesquisado, mas estudado ou aplicado a um contexto que ainda não foi abordado.

Em se tratando da formulação de uma pergunta a partir de uma curiosidade, ou de uma dúvida, a intervenção do professor tem por objetivo fazer o aluno refletir a respeito da pergunta inicial que ele propõe. Por exemplo: a pergunta exige, de fato, a realização de um trabalho investigativo para que possa ser respondida? Assim, quando o aluno pergunta: "Qual o índice de mortes de trânsito no Brasil?", de imediato o professor percebe que a pergunta pode ser facilmente resolvida mediante uma simples consulta às fontes de informação. O professor, entretanto, não precisa criticar a pergunta para convencer o aluno a reformulá-la.

Que intervenções poderiam, então, ser feitas por você, professor orientador, nesse momento? Uma possibilidade é dialogar com o grupo e propor um exame momentâneo de outra curiosidade que, semelhante à primeira, também não exige um projeto investigativo. Por exemplo, "Quais os malefícios causados pelo cigarro?". Para saber, basta consultar fontes de informação, como livros, internet. Dessa forma, o professor mostra que essa curiosidade não exige do "investigador" nada além de uma leitura da resposta que já se encontra pronta. Assim, os alunos perceberão que a pergunta não demanda uma investigação propriamente dita. 


\section{Avaliação}

A definição do problema está clara e bem delimitada para poder conduzir a uma possível solução?

Segundo Moura e Barbosa (2017), deve haver adequação entre o problema selecionado e a capacidade de empreendimento do grupo que pretende realizar o projeto, tendo em conta as competências, os recursos e o tempo disponível.

Nesse ponto, é adequado que os alunos tenham um tempo livre para retomar suas curiosidades ou dúvidas, de modo que possam reelaborar o problema de pesquisa em sintonia com as trocas de ideias e de acordo com suas capacidades de compreensão no momento.

Para saber mais...

No livro Métodos e técnicas de pesquisa social, Gil (2002, p. 37-39) cita algumas regras práticas para a formulação de um problema científico.

GIL, Antonio Carlos. Métodos e técnicas de pesquisa social. 6. ed. São Paulo: Atlas, 2002. Disponível em: https://abre.ai/c6SY. Acesso em: 15 out. 2017.

\section{Justificativa - Por que investigar?}

Nessa etapa busca-se apresentar respostas à questão "do porquê" da realização da investigação. Dessa forma, o professor deve verificar qual é a argumentação dos alunos sobre as razões para investigar o problema. É preciso deixar claro que se trata de um exercício para o qual não é suficiente o aluno dizer que a escolha daquela curiosidade ou dúvida recai num vago interesse.

Sem dúvida, o problema deve interessar a quem pesquisa. A justificativa para investigar, entretanto, exige que o aluno investigador coloque o foco na relevância do estudo. Mostrar a relevância significa, 
por exemplo, chamar a atenção para a importância de se conhecer mais sobre um determinado assunto que contribuirá para dar sequência aos estudos que ele e os colegas estão realizando na classe. Ou ainda destacar que o estudo irá trazer algum benefício às pessoas da comunidade escolar, etc.

Para Moura e Barbosa (2017), a extensão e a complexidade da justificativa dependem do contexto e da complexidade do projeto. Há casos em que a apresentação clara do problema de pesquisa é considerada suficiente para justificar a pesquisa. Por outro lado, os projetos em que o tema gerador é complexo e pouco conhecido, há necessidade de uma justificativa mais abrangente e bem fundamentada.

Para saber mais...

No livro Metodologia do trabalho científico, Prodanov e Freitas (2013, p. 82-84) enfatizam quais elementos devem ser abordados na justificativa. PRODANOV, Cleber Cristiano; FREITAS, Ernani Cesar de. Metodologia do trabalho científico: métodos e técnicas da pesquisa e do trabalho acadêmico. 2. ed. Novo Hamburgo: FREEVALE, 2013. Disponível em: https://abre.ai/c6S3. Acesso em: 5 out. 2017.

Avaliação

O estudo realizado está ligado ao contexto regional e local apresentando contribuições para a geração de novos conhecimentos?

O grupo explicitou a relevância de sua pesquisa?

Hipóteses - Quais as possíveis respostas para o problema?

As hipóteses são as possíveis respostas para o problema de pesquisa. Apoiam-se em saberes prévios dos alunos e, também, em um levantamento de informações e conhecimentos em fontes de consulta disponíveis. 
Lembre-se, professor!

É importante que o professor auxilie seus alunos a identificarem a necessidade de formular hipóteses para o trabalho que será realizado.

Segundo Gil (2002, p. 39), quando “[...] o objetivo é o de descrever um fenômeno ou características de um grupo, as hipóteses não são enunciadas formalmente", e também "[...] pode ser que o objetivo da pesquisa seja: testar uma hipótese" (GIL, 2002, p. 112). Então, nesse caso, não há necessidade de se colocar formalmente uma hipótese, só o objetivo.

Já para pesquisas experimentais, por exemplo, "que envolvem associação de variáveis causais, as hipóteses devem ser enunciadas formalmente" (GIL, 2002, p. 94).

Para saber mais...

No livro Como elaborar projetos de pesquisa, Antônio Carlos Gil (2002, p. 31-40) discute sobre a formulação de hipóteses em um trabalho de pesquisa.

GIL, Antônio Carlos. Como elaborar projetos de pesquisa. 4. ed. São Paulo: Atlas, 2002. Disponível em: https://abre.ai/daNS. Acesso em: 15 out. 2017.

Avaliação

As hipóteses levantadas correspondem ao problema de pesquisa e podem ser verificadas? 


\section{Objetivos - Para que investigar?}

A definição dos objetivos determina o que o pesquisador quer atingir com a realização do projeto de pesquisa, e eles devem ser sempre expressos em verbos de ação. Os objetivos dividem-se em geral e específicos. Conforme Moura e Barbosa (2017):

» Objetivo geral: é muito semelhante à pergunta estabelecida no problema da pesquisa, com a diferença de que o objetivo deve sempre começar com o verbo no infinitivo, indicando a ação a ser realizada para responder à questão proposta pela pesquisa.

» Objetivos específicos: referem-se às etapas da pesquisa que, em conjunto, levam ao cumprimento do objetivo geral. Expõem o que se pretende alcançar durante a aplicação da pesquisa. Assim como o objetivo geral, os verbos devem ser utilizados no infinitivo.

Para saber mais...

Exemplos aplicáveis a objetivos podem ser encontrados em:

PRODANOV, Cleber Cristiano; FREITAS, Ernani Cesar de. Metodologia do trabalho científico: métodos e técnicas da pesquisa e do trabalho acadêmico. 2. ed. Novo Hamburgo: FREEVALE, 2013. p. 124-125.

Avaliação

O objetivo geral é factível e os objetivos específicos respondem adequadamente a ele? 


\section{Revisão bibliográfica - O que já foi investigado sobre o tema?}

Como o próprio nome indica, nessa etapa são analisados os trabalhos científicos mais recentes que tratam do assunto ou que dão embasamento teórico e metodológico para o desenvolvimento da pesquisa, bem como conhecer as contribuições dos outros pesquisadores. Além disso, é aqui que são explicitados os principais conceitos e termos técnicos a serem utilizados na pesquisa.

A partir das ideias de Behrens (2015), apresenta-se uma proposta para o professor auxiliar seus alunos na realização da revisão bibliográfica sobre o tema da pesquisa.

\section{Lembre-se, professor!}

É importante que o professor indique fontes de pesquisa e bibliografias dos assuntos que aparecerem ao longo do projeto para incentivar os alunos a expandirem cada vez mais seu horizonte de pesquisa. Além disso, os alunos precisam ser alertados sobre os cuidados que deverão ter ao realizarem a pesquisa, por exemplo, os conhecimentos apresentados nos sites podem conter conteúdos de qualidade duvidosa, assim, os alunos precisam aprender a acessar sites que apresentem qualidade e que tenham como origem fontes confiáveis.

Inicialmente propõe-se que os alunos pesquisem individualmente. Embora a metodologia de projetos proponha um trabalho coletivo, ela contempla a ação individual, pois,

O equilíbrio entre o trabalho individual e coletivo deve ser observado pelo professor por dois motivos significativos: primeiro, o de estimular individualmente os alunos a buscarem os referenciais necessários para a pesquisa; e segundo, para que esse esforço seja promulgado e valorizado perante os colegas. Não se trata de instalar a competitividade, mas de valorizar o envolvimento e a competência na investigação desencadeada pelo aluno. (BEHRENS, 2000, p. 113). 
Nesse momento é importante que o professor estimule seus alunos a buscar informações nas mais variadas fontes, buscando compartilhá-las com os outros integrantes do grupo.

Lembre-se, professor!

Antes de os alunos iniciarem suas produções textuais, sugere-se que professor discuta com eles sobre como referenciar os autores utilizados, como fazer citações e sobre a importância das regras da Associação Brasileira de Normas Técnicas (ABNT).

A partir das informações recolhidas nas pesquisas, sugere-se que cada aluno produza um texto individual. É importante que nessa etapa o professor auxilie seus alunos para que não apresentem produções copiadas e sem significado, mas com uma visão crítica e reflexiva sobre os dados e informações que trouxerem para a sala de aula, isto é, o desafio é produzir um texto com qualidade, pertinência e clareza de ideias.

Após seria interessante que os alunos apresentassem seus textos individuais, com o objetivo de promover uma discussão crítica e reflexiva, pois os alunos terão a oportunidade de desenvolver suas ideias criticamente, além de levar a reflexões pertinentes, a aceitarem as diferenças, as opiniões contrárias, as parcerias entre os colegas.

De acordo com Behrens (2005), esse procedimento permite que os alunos argumentem e defendam suas ideias sobre a temática investigada, e com amadurecimento crítico e reflexivo possam acolher as opiniões dos colegas ou defender suas próprias convicções.

Por último, sugere-se que os alunos produzam um texto coletivo, de forma que possa reunir as produções individuais, as reflexões e as contribuições da discussão coletiva. Nesse momento, o professor deve orientar os alunos levando-os a discutir sobre os pontos convergentes e divergentes, que se tornarão subsídios para uma produção crítica e de qualidade. 
Segundo Behrens (2006), a fase de produção coletiva provoca o trabalho entre pares e permite acoplar e interconectar as produções individuais realizadas pelos alunos. Nessa fase, há necessidade de retomar a problemática e orientar os alunos para a produção coletiva no projeto, pois a falta de orientação do docente pode levar os alunos a acumularem suas produções individuais, sem discuti-las e sem elaborá-las.

Lembre-se, professor!

Recomenda-se que a produção coletiva seja entregue com as produções individuais, a fim de se acompanhar o desenvolvimento de cada aluno e a participação de todos no projeto.

Para saber mais...

No livro Metodologia do trabalho científico, Prodanov e Freitas (2013, p. 131-138) discutem sobre a revisão bibliográfica de uma pesquisa. PRODANOV, Cleber Cristiano; FREITAS, Ernani Cesar de. Metodologia do trabalho cientifico: métodos e técnicas da pesquisa e do trabalho acadêmico. 2. ed. Novo Hamburgo: FREEVALE, 2013. p. 131-138.

As referências a seguir tratam sobre as regras da ABNT:

Normas e regras ABNT - Regras para TCC e monografias. Disponível em: https://abre.ai/c7yK. Acesso em: 19 out. 2017.

Normas da ABNT - Citações e referências bibliográficas. Disponível em: https://abre.ai/c6TG. Acesso em: 19 out. 2017. 


\section{Avaliação}

O estudo está situado e consegue estabelecer relações com pesquisas similares?

As ideias expostas foram referendadas?

As informações foram extraídas de fontes confiáveis?

Todos os autores citados foram referenciados?

As citações e referências estão de acordo com as regras da ABNT?

\section{Metodologia - Como investigar?}

Nessa etapa, segundo Moura e Barbosa (2017), o professor orientador e os alunos precisam especificar todas as ações, atividades e tarefas que deverão ser desenvolvidas para que o projeto alcance os resultados esperados.

Segundo Diniz e Silva (2008), a metodologia compreende a descrição formal dos métodos e técnicas a serem utilizados na pesquisa, esclarecendo o tipo de pesquisa, definindo o caminho a ser percorrido, o método de abordagem e o método de procedimentos; os instrumentos de coleta de dados, o universo da pesquisa e a seleção da amostra.

\section{Lembre-se, professor!}

O professor deve certificar-se de que o aluno irá conduzir suas pesquisas de maneira segura e respeitando a ética.

As pesquisas que trabalharem com seres humanos devem elaborar um termo de consentimento livre e esclarecido. O modelo do termo deve vir como anexo, preservando eticamente os participantes através do sigilo das informações confidenciais, participação voluntária e da desistência em participar do estudo em qualquer fase da pesquisa. Também deve ressaltar a importância de a metodologia ser escrita de maneira precisa e clara, possibilitando a repetição dos procedimentos com a mesma precisão. 
Na metodologia deve ficar claro: Onde? Quem? Ou seja, deve ficar claro o local, a população investigada com suas características ou, se for o caso, a delimitação da amostra e o modo como será feita sua seleção e as variáveis investigadas.

Também devem ser descritos os procedimentos utilizados na pesquisa (Como? Com quê?) para obtenção dos dados, a descrição das técnicas a serem usadas e os instrumentos de coleta de dados: questionários, formulários, roteiros de entrevistas, ficha de observação, etc., bem como justificar a adequação de uns aos outros. Deve ainda evidenciar o tratamento dos resultados, ou seja, mostrar como será feita a tabulação, a análise e o tratamento dos dados.

\section{Para saber mais...}

No livro Fundamentos da metodologia científica, Marconi e Lakatos (2003, p. 174-213) descrevem as técnicas de pesquisas que podem ser utilizadas como instrumento de coleta de dados.

MARCONI, Marina de Andrade; LAKATOS, Eva Maria. Fundamentos de metodologia científica. 5. ed. São Paulo: Atlas, 2003. Disponível em: https://abre.ai/c7yG. Acesso em: 18 out. 2017.

Sugestões para a elaboração do Termo de Consentimento Livre e Esclarecido o professor encontra em:

FSA. Sugestões para a elaboração do Termo de Consentimento Livre e Esclarecido (TCLE). Disponível em: https://abre.ai/c7yH. Acesso em: 22 dez. 2017.

\section{Avaliação}

É apresentado um método eficiente e confiável para resolver o problema? A metodologia está descrita claramente e permite cumprir o objetivo geral?

As variáveis foram bem identificadas e definidas? 
Sugere-se que após essa etapa da elaboração do projeto, os grupos apresentem seu planejamento na sala de aula para o restante da turma, com o objetivo de discutir e aperfeiçoar suas propostas.

\section{Cronograma - quando investigar?}

O cronograma é um planejamento adequado do tempo que os alunos terão para realizar o trabalho, especificando as atividades a serem cumpridas. Conforme Moura e Barbosa (2017), é elaborado a partir das análises da sequência de atividades e suas durações, para criar um escalonamento lógico e organizado para todo o projeto. O tempo pode ser dividido em dias, semanas, quinzenas, meses, etc. A seguir é apresentado um modelo de cronograma.

Lembre-se, professor!

Cabe ao professor junto com os alunos estabelecer um cronograma para a realização do projeto investigativo. Como se pressupõe que primeiramente o trabalho a ser realizado participará da feira interna da escola, deve-se estabelecer um prazo final que anteceda a data do evento.

\section{Avaliação}

Todas as etapas do projeto estão estabelecidas no cronograma?

É possível realizar todas as atividades dentro dos prazos estabelecidos? 
Quadro 7.1 - Modelo de cronograma

\begin{tabular}{|c|l|l|l|l|l|l|l|l|}
\hline $\begin{array}{c}\text { ATIVIDADEs/ } \\
\text { PERíodos }\end{array}$ & Fev. & Mar. & Abr. & Maio & Jun. & Jul. & Ago. & Set. \\
\hline $\begin{array}{c}\text { Elaboração do } \\
\text { escopo da pesquisa }\end{array}$ & $\mathrm{X}$ & & & & & & & \\
\hline $\begin{array}{c}\text { Revisão } \\
\text { bibliográfica }\end{array}$ & $\mathrm{X}$ & $\mathrm{X}$ & & & & & & \\
\hline $\begin{array}{c}\text { Elaboração da } \\
\text { fundamentação } \\
\text { metodológica }\end{array}$ & & $\mathrm{X}$ & & & & & & \\
\hline $\begin{array}{c}\text { Apresentação do } \\
\text { plano de pesquisa } \\
\text { para a turma }\end{array}$ & & & $\mathrm{X}$ & & & & & \\
\hline $\begin{array}{c}\text { Organização do } \\
\text { instrumento de } \\
\text { coleta de dados }\end{array}$ & & & $\mathrm{X}$ & & & & & \\
\hline $\begin{array}{c}\text { Execução do plano } \\
\text { de pesquisa } \\
\text { (coleta dos dados }\end{array}$ & & & & & & & & \\
\hline $\begin{array}{c}\text { Tabulação e apre- } \\
\text { sentação de dados }\end{array}$ & & & & & & & & \\
\hline $\begin{array}{c}\text { Análise e } \\
\text { interpretação dos } \\
\text { dados coletados }\end{array}$ & & & & & & & & \\
\hline $\begin{array}{c}\text { Elaboração do } \\
\text { relatório final }\end{array}$ & & & & & & & & \\
\hline $\begin{array}{c}\text { Revisão do texto } \\
\text { Apresentação do } \\
\text { projeto investigativo } \\
\text { realizado } \\
\text { para a turma } \\
\begin{array}{c}\text { Participação } \\
\text { naira de ciências } \\
\text { da escola }\end{array}\end{array}$ & & & & & & & & \\
\hline
\end{tabular}

Fonte: Elaborado pelos autores. 


\section{Recursos - Com o que investigar?}

Nos recursos são indicados todos os materiais ou equipamentos necessários para realizar todas as etapas do projeto, tais como: despesas de custeio (remuneração de serviços pessoais, materiais de consumo, outros serviços de terceiros e encargos), despesa de capital (equipamentos e material permanente).

Lembre-se, professor!

Os alunos devem indicar quais serão os recursos necessários para a realização do projeto investigativo, e cabe ao professor verificar os recursos já disponíveis e quais os recursos necessários não disponíveis e como poderão ser obtidos.

\section{Avaliação}

Foram indicados todos os recursos necessários para realizar todas as etapas do projeto?

É possível obter todos os recursos indicados?

\section{Execução plano de pesquisa}

A execução do plano de pesquisa é a etapa em que os dados serão coletados através das técnicas estabelecidas para a resolução do problema. Nesse momento, é importante que o professor participe da delegação das atividades, sempre que possível acompanhe as execuções e também deve cuidar de manter a equipe integrada e motivada.

\section{Análise dos dados}

Nessa etapa analítica e descritiva da pesquisa, após os dados serem coletados, é preciso organizá-los. Convém ressaltar que para cada técnica utilizada deve corresponder um tratamento adequado à 
sua natureza. Os recursos computacionais podem ser escolhidos para dar suporte na elaboração de índices e cálculos estatísticos, tabelas, quadros e gráficos.

A partir dos dados organizados, o próximo momento consiste em sua análise e interpretação. Essa análise deve ser feita a fim de atender aos objetivos da pesquisa, comparar e confrontar a abordagem teórica com uma pesquisa anterior e destacar o que a investigação de campo aporta de singular como contribuição.

Lembre-se, professor!

Nessa etapa, você, professor, poderá auxiliar os alunos a decidir como os dados serão tratados, e pode buscar colaboração do professor de matemática para a elaboração de gráficos, tabelas e cálculos estatísticos.

$\mathrm{Na}$ análise e interpretação dos dados, sugere-se que, inicialmente, oriente seus alunos a identificar os aspectos novos e interessantes que apareceram durante a tabulação, de forma que os dados coletados sejam analisados e discutidos relacionando-os com a revisão bibliográfica e complementados com o posicionamento dos próprios alunos.

Segundo Ramos (2012), nessa etapa serão buscadas as respostas para os questionamentos, ou seja, do problema de investigação. Para isso é necessário construir argumentos que fundamentem as respostas aos questionamentos dos envolvidos no processo da pesquisa. Os argumentos devem ser fundamentados a partir de ideias que não sejam de senso comum, mas estabelecidas por autores referenciados. Segundo Moraes (2012), saber argumentar é defender seus pontos de vista. O autor afirma que os argumentos devem ter "qualidade formal e científica", isto é, "ler livros, explorar teorias, consultar autores no sentido de encontrar elementos que ajudem a fundamentar os argumentos em construção" (MORAES, 2012, p. 97).

Adaptado da proposta de Dutra et al. (2014), após são sugeridas as rodadas de discussões. Nessa estratégia, os alunos apresentam seus resultados para os demais grupos da sala, com o intuito de que os colegas opinem, discutam, façam sugestões e tirem dúvidas ao longo 
das interações e trocas de uns com os outros. Além disso, acredita-se que esse processo contribuirá para a aprendizagem de todos os alunos.

As rodadas podem ser programadas no formato de seminários, com o propósito pedagógico de conseguir que os alunos se sintam acolhidos, valorizados, capazes de ajudar e serem ajudados pelos demais colegas. Outro propósito é a troca de ideias voltadas às aprendizagens do método e das construções conceituais, na medida em que os participantes têm a chance de expor o trabalho em andamento. O produto que resultará dessas análises é um conjunto de relações entre os dados, voltado à formação de sentido e que nos permitirá elaborar uma resposta possível para o problema de investigação.

\section{Avaliação}

As discussões dos resultados se mostram bem argumentadas e fundamentadas em fontes científicas e respondem às hipóteses e aos objetivos chegando a conclusões significativas?

Os dados coletados foram suficientes para sustentar as conclusões apresentadas?

A solução proposta é viável para o problema estudado?

\section{Relatório final}

Essa é a etapa final do projeto investigativo, na qual a pesquisa será apresentada em forma de texto. Aqui será apresentada uma sugestão de modelo de relatório (conforme Apêndice 1) para projetos investigativos, baseada na ABNT NBR 14.724 de 2011. Conforme esse documento, há elementos obrigatórios e opcionais. Dessa forma, os alunos junto com o professor podem adequar conforme julgar necessário.

Os elementos na estrutura se dividem em: pré-textuais, textuais e pós-textuais. O Quadro 7.2 mostra essa divisão com os respectivos elementos obrigatórios e opcionais. 
Quadro 7.2 - Elementos textuais do relatório final

\begin{tabular}{|l|l|}
\hline Estrutura & Elementos \\
\hline Elementos pré-textuais & Capa \\
& $\begin{array}{l}\text { Folha de rosto } \\
\text { Dedicatória(s) } \\
\text { Agradecimento(s) }\end{array}$ \\
& $\begin{array}{l}\text { Resumo } \\
\text { Lista de ilustrações } \\
\text { Lista de abreviaturas e siglas } \\
\text { Sumário }\end{array}$ \\
\hline Elementos textuais & $\begin{array}{l}\text { Introdução (problema, justificativa e } \\
\text { objetivos) } \\
\text { Desenvolvimento (inclui a revisão } \\
\text { bibliográfica, a metodologia e os } \\
\text { resultados) } \\
\text { Conclusão }\end{array}$ \\
\hline Elementos pós-textuais & $\begin{array}{l}\text { Referências } \\
\text { Apêndice(s) } \\
\text { Anexo(s) }\end{array}$ \\
\hline
\end{tabular}

* Elementos opcionais ou condicionados à necessidade.

Fonte: Adaptado da ABNT NBR 14.724, 2011.

Sugere-se que o professor apresente o modelo do relatório e ofereça auxílio aos alunos conforme suas dúvidas e dificuldades forem surgindo. No caso do resumo, das listas e sumário, podem ser apresentados alguns exemplos desses elementos em trabalhos científicos.

\section{Referências}

BEHRENS, Marilda Aparecida. Metodologia de projetos: aprender e ensinar para a produção do conhecimento numa visão complexa. In: TORRES, Patrícia Lupion (org.). Metodologias para a produção do conhecimento: da concepção à prática. Curitiba: SENAR-PR, 2015. p. 97-116. 
BEHRENS, Marilda Aparecida. O paradigma da complexidade: metodologia de projetos, contratos didáticos e portfólios. Petrópolis: Vozes, 2006.

BEHRENS, Marilda Aparecida. O paradigma emergente e a prática pedagógica. Petrópolis: Vozes, 2005.

BEHRENS, Marilda Aparecida. Projetos de aprendizagem colaborativa num paradigma emergente. In: MORAN, José Manuel; MASETTO, Marcos T.; BEHRENS, Marilda Aparecida (org.). Novas tecnologias e mediação pedagógica. Campinas: Papirus, 2000.

DINIZ, Célia Regina; SILVA, Iolanda Barbosa da. Metodologia científica. 21. ed. Campina Grande: UEPB, EDUEPB; Natal: UFRN, 2008.

DUTRA, Italo Modesto et al. Trajetórias criativas: jovens de 15 a 17 anos no ensino fundamental: uma proposta metodológica que promove autoria, criação, protagonismo e autonomia: caderno 7: iniciação científica. Brasília: Ministério da Educação, 2014.

GIL, Antônio Carlos. Como elaborar projetos de pesquisa. 4. ed. São Paulo: Atlas, 2002. Disponível em: https://abre.ai/c6UJ. Acesso em: 15 out. 2017. MARCONI, Marina de Andrade; LAKATOS, Eva Maria. Fudamentos de metodologia científica. 5. ed. São Paulo: Atlas, 2003. Disponível em: https://abre.ai/c6UH. Acesso em: 18 out. 2017.

MORAES, Roque. Educar pela pesquisa: exercício de aprender a aprender. In: MORAES, Roque; LIMA, Valderez Marina do Rosário (org.). Pesquisa em sala de aula: tendências para a educação em novos tempos. 3. ed. Porto Alegre: EDIPUCRS, 2012. p. 93-104.

MOURA, Dácio Guimarães; BARBOSA, Eduardo Fernandes. Trabalhando com projetos: planejamento e gestão de projetos educacionais. Petrópolis: Vozes, 2017. E-book.

RAMOS, Maurivan Güntzel. Educar pela pesquisa é educar para a argumentação. In: MORAES, Roque; LIMA, Valderez Marina do Rosário (org.). Pesquisa em sala de aula: tendências para a educação em novos tempos. 3. ed. Porto Alegre: EDIPUCRS, 2012. p. 21-38.

ROSA, Paulo Ricardo da Silva. Algumas questões relativas a feiras de ciências: para que servem e como devem ser organizadas. Caderno Brasileiro de Ensino de Física, Campo Grande, MS: UFMS, v. 12, n. 3, p. 223-228, 1995. 


\section{Capítulo 8 \\ Comunicando o projeto investigativo}

Após o projeto investigativo ser concluído é o momento de comunicar o trabalho. Durante a comunicação é importante que se consiga passar confiança e clareza àqueles que assistem à apresentação, para que o trabalho tenha maior credibilidade. Para isso é essencial uma boa apresentação oral e corporal e um pôster também pode auxiliar.

O professor pode disponibilizar o modelo para os grupos e indicar algumas sugestões para a elaboração do pôster, além de oferecer dicas para uma comunicação oral e corporal adequada. A seguir são indicadas algumas referências. 
Lembre-se, professor!

Antes da impressão do pôster, é fundamental que o professor faça uma revisão atenta da ortografia, e se necessário indique modificações para uma apresentação mais clara e compreensível.

Depois do pôster pronto, os grupos devem se preparar para a apresentação. Sugere-se que o trabalho seja apresentado para a turma na sala de aula antes de participarem da feira de ciências da escola. Isso poderá contribuir na aprendizagem dos colegas, assim como estes poderão oferecer contribuições ao trabalho que lhes for apresentado.

Para saber mais...

Referências que tratam sobre como elaborar um pôster:

MELLO, Marco. Como fazer um pôster científico. Publicado em 13 mar. 2012. Disponível em: https://abre.ai/c690. Acesso em: 20 out. 2017.

DANTAS, Lys M. V.; OLIVEIRA, Adriano A. Como elaborar um pôster acadêmico: material didático de apoio à vídeo-dica Pôster Acadêmico. Projeto de Extensão UFRB. Cachoeira: UFRB, 2015. Disponível em: https://abre.ai/c69X. Acesso em: 20 out. 2017.

A próxima referência trata sobre dicas de comunicação oral e corporal: FEBRACE. Dicas para você: dicas de comunicação oral e corporal. Disponível em: https://abre.ai/daNT. Acesso em: 20 out. 2017. 


\section{Capítulo 9}

\section{Autoavaliação para os alunos e para o professor}

Após os projetos investigativos serem apresentados na feira de ciências da escola, sugere-se que o professor aplique aos alunos um questionário de autoavaliação. Isso possibilitará identificar as percepções dos próprios alunos em relação às contribuições pessoais trazidas, às modificações no processo de ensino-aprendizagem através da feira de ciências e às contribuições gerais desse tipo de evento. Ainda no mesmo questionário, visando potencializar e aprimorar o trabalho do professor e as próximas atividades relacionadas aos projetos investigativos, sugere-se aos alunos observarem mais alguns questionamentos abertos.

Já o questionário de autoavaliação do professor visa auxiliar o docente a identificar aspectos positivos durante a orientação dos projetos realizados, bem como analisar aspectos que necessitam ser adequados para potencializar cada vez mais a realização de projetos investigativos. 
A seguir são apresentadas as sugestões de questionários de autoavaliação. O primeiro destina-se aos alunos e o segundo ao professor. Ressalta-se que o questionário pode ser adaptado conforme o professor julgar mais adequado.

Quadro 9.1 - Autoavaliação dos alunos

Prezado aluno,

Para as contribuições pessoais trazidas, as modificações no processo de ensinoaprendizagem através das feiras de ciências e as contribuições gerais desse tipo de evento, indique o número que melhor descreve seu nível de conhecimento ANTES e DEPOIS de se envolver em projetos investigativos realizados para feiras de ciências.

\begin{tabular}{|l|c|c|}
\hline $\begin{array}{l}\text { 0- Nenhum } \quad \text { - Muito Bom } \\
\text { 1- Muito ruim } \quad \text { 5 - Excelente } \\
\text { 2- Ruim } \quad \text { - Não se aplica } \\
\text { 3- Bom }\end{array}$ & $\begin{array}{c}\text { ANTES } \\
\text { de participar de } \\
\text { projetos para } \\
\text { feiras de ciências }\end{array}$ & $\begin{array}{c}\text { DEPOIs } \\
\text { de participar de } \\
\text { projetos para } \\
\text { feiras de ciências }\end{array}$ \\
\hline Comunicação oral & & \\
\hline Comunicação escrita & & \\
\hline Pensamento crítico & & \\
\hline Trabalho/estudo em equipe & & \\
\hline Trabalho/estudo individual & & \\
\hline Espírito de liderança & & \\
\hline Leitura e compreensão de textos & & \\
\hline Espírito investigativo & & \\
\hline Raciocínio matemático & & \\
\hline Raciocínio lógico & & \\
\hline Motivação para os estudos & & \\
\hline Gosto por pesquisa & & \\
\hline Organização pessoal/gestão de tempo & & \\
\hline
\end{tabular}




\begin{tabular}{|l|l|l|}
\hline Interesse em aprender coisas novas & & \\
\hline Iniciativa & & \\
\hline Curiosidade & & \\
\hline Criatividade & & \\
\hline Autoconfiança & & \\
\hline Persistência & & \\
\hline Habilidades manuais & & \\
\hline Tomada de decisões & & \\
\hline Análise e interpretação de dados & & \\
\hline Trabalhos experimentais e laboratoriais & & \\
\hline $\begin{array}{l}\text { Empreendedorismo/visão } \\
\text { empreendedora }\end{array}$ & & \\
\hline Gerência e planejamento de atividades & & \\
\hline Invenção e inovação & & \\
\hline Conhecimentos multidisciplinares & & \\
\hline $\begin{array}{l}\text { Identificação, formulação e solução } \\
\text { de problemas }\end{array}$ & & \\
\hline $\begin{array}{l}\text { Estipular e cumprir cronogramas, prazo } \\
\text { e metas }\end{array}$ & & \\
\hline $\begin{array}{l}\text { Aplicação de ferramentas matemáticas } \\
\text { e tecnológicas }\end{array}$ & & \\
\hline Desenho técnico & & \\
\hline Noção espacial & & \\
\hline Eletrônica & & \\
\hline Robótica & & \\
\hline Uso do computador & & \\
\hline Hábito de leituras científicas & & \\
\hline
\end{tabular}

Fonte: DEPIERI, 2015, p. 122. 
Ainda sobre a realização do projeto investigativo e sua participação na feira de ciências, responda.

1) Se você fosse atribuir uma nota de 1 a 10 sobre a sua aprendizagem com a participação em feiras de ciências, que nota você daria? Justifique sua resposta.

2) Caso você pudesse agora refazer o seu trabalho apresentado na feira de ciências, o que você faria diferente? Por quê?

3) Comparativamente ao ensino em sala de aula, você considera que houve maior aprendizagem, menor ou igual relativa ao conteúdo de seu trabalho apresentado na feira de ciências? Se sim, em quais aspectos?

4) Se pudesse sugerir algo diferente ao orientador de seu trabalho na feira de ciências, o que diria?

5) Em relação ao seu aprendizado com a execução do trabalho e participação na feira de ciências, o que você sugeriria a seu professor de sala de aula modificar para que a aprendizagem fosse mais efetiva?

Fonte: Adaptado de DEPIERI, 2015, p. 122. 
Quadro 9.2 - Questionário de autoavaliação do professor

1) Consegui definir logo no início do ano os assuntos que seriam trabalhados ao longo do ano letivo?

( ) sempre ( ) na maioria das vezes ( ) às vezes ( ) raramente ( ) nunca

2) Consegui adequar os temas dos projetos investigativos ao assunto estudado em sala de aula?
( ) sempre
( ) na maioria das vezes
( ) às vezes
( ) raramente
( ) nunca

3) Incentivei o pensamento crítico dos meus alunos na realização dos projetos investigativos?
( ) sempre
( ) na maioria das vezes
( ) às vezes
( ) raramente
( ) nunca

4) Incentivei meus alunos a trabalharem em grupo?
( ) sempre
( ) na maioria das vezes
( ) às vezes
( ) raramente
( ) nunca

5) Consegui incentivar meus alunos a realizar projetos investigativos?
( ) sempre
( ) na maioria das vezes
( ) às vezes
( ) raramente
( ) nunca

6) Auxiliei e acompanhei os registros feitos pelos alunos no diário de bordo?
( ) sempre
( ) na maioria das vezes
( ) às vezes
( ) raramente
( ) nunca

7) Consegui com que os alunos relacionassem os temas tratados nos projetos investigativos com outras áreas do conhecimento?
( ) sempre
( ) na maioria das vezes
( ) às vezes
( ) raramente
( ) nunca

8) Consegui estabelecer um planejamento para atender às dúvidas dos alunos?
( ) sempre
( ) na maioria das vezes
( ) às vezes
( ) raramente
( ) nunca

Fonte: Elaborado pelos autores.

\section{Referência}

DEPIERI, Adriana Anunciatto. A engenharia sob a ótica dos pré-universitários e o impacto das feiras de ciências. 2014. $304 \mathrm{f}$. Tese (Doutorado em Engenharia Elétrica) - Escola Politécnica da Universidade de São Paulo, São Paulo, 2014. 


\section{Considerações finais}

Agora é o momento de você, professor, colocar tudo em prática. Sinta-se à vontade para fazer adaptações de acordo com suas necessidades.

Lembre-se de que projetos investigativos nascem a partir de problemas, necessidades e oportunidades e também de desafios identificados pelos alunos, proporcionando questionamentos e argumentação e, por fim, os conhecimentos produzidos devem ser comunicados.

Este Guia é apenas um ponto de partida. O professor deve incentivar a curiosidade de seus alunos, buscando realizar investigações científicas no âmbito escolar. Busque eventos de iniciação científica para você e seus alunos participarem. Com certeza será uma oportunidade que trará grandes experiências e aprendizado para todos os envolvidos.

Bom trabalho, desejamos sucesso para você e seus alunos! 
A pêndice

Modelo de relatório 
NOME DA ESCOLA

NOME DOS AUTORES

Junto com o nome de cada autor, é interessante acrescentar o endereço de e-mail, pois, durante o evento, os visitantes podem ter dúvidas ou outros interesses sobre o projeto investigativo apresentado e, posteriormente, podem entrar em contato com os autores.

\section{TÍTULO DO PROJETO \\ INVESTIGATIVO}

CIDADE-ESTADO

ANO

NOME DA ESCOLA

\section{CATEGORIA}

(ensino médio ou ensino fundamental) 


\title{
TÍTULO DO PROJETO INVESTIGATIVO
}

\author{
Nomes dos alunos \\ Turma \\ Disciplina - Professor
}

CIDADE-ESTADO

ANO 


\section{Dedicatória (opcional) ${ }^{1}$}

O trabalho poderá ser dedicado a alguém (familiares, amigos ou outros), em forma de texto ou apenas mencionando a pessoa a quem se dedica. Deverá ser usada uma página do relatório apenas para isso, alinhando-se o texto, preferencialmente, à margem inferior direita e à esquerda, em espaço de parágrafo. Quando houver fonte a ser referenciada, deve-se alinhá-la à margem direita.

\section{Agradecimentos (opcional)}

Os agradecimentos podem ser feitos de forma sucinta e restrita ou enfática, dirigida a uma pessoa, ou mais, à instituição ou à empresa. No caso de serem breves, eles podem ser feitos na introdução do relatório; porém, quando o autor pretende destacá-los, ou incluir mais pessoas ou instituição, deve fazer à parte, usando uma página apenas para isso.

\section{Resumo}

O resumo é a apresentação concisa dos pontos relevantes do trabalho. Indica apenas os pontos principais, informando ao leitor para que ele possa decidir sobre a conveniência ou não da leitura do trabalho. Assim, logo no início, deve deixar claro qual o tema que será explorado no relatório, ressaltando o objetivo, a metodologia, os resultados e as conclusões do trabalho.

Deve ser escrito em um só parágrafo, com espaçamento simples e acompanhado das palavras-chave (até cinco palavras ou expressões no máximo), separadas por ponto. Quanto à extensão, os resumos devem ter de 150 a 500 palavras.

Apenas por uma questão de organização da apresentação da descrição dos elementos de um relatório, foram citados de maneira consecutiva todos os elementos. No entanto, conforme a ABNT, cada elemento deve ser apresentado usando uma nova página do relatório. 


\section{Listas (opcional)}

As listas consistem na relação sequencial de títulos de tabelas, quadros, gráficos e figuras constantes do trabalho, acompanhados dos respectivos números de páginas.

Dessa forma, para tabelas, quadros, gráficos e figuras deverá existir uma numeração distinta e sequencial ao longo do texto. Sobre eles devem constar, além da numeração, a legenda (ou título), precedida da palavra (tabela, quadro, gráfico, ou figura, etc.) e do número correspondente, também não pode faltar a referência à fonte, esta deve ser localizada abaixo.

Se o número de elementos de cada item for inferior a cinco, elaborar-se-á uma única listagem contendo tabelas, quadros, gráficos e ilustrações.

A regra da lista vale também para símbolos e siglas. Caso haja um número significativo deles, devem ser relacionados em ordem alfabética, acompanhados do respectivo significado.

\section{Sumário}

Denomina-se sumário a enumeração das principais divisões, seções, capítulos e subcapítulos de um trabalho.

\section{Introdução}

A introdução corresponde à abertura do texto do relatório apresentado. Uma boa introdução deve conter aspectos realmente importantes sobre o tema, pois somente assim o leitor poderá se sentir motivado a avançar na sua leitura. Dessa forma, sugere-se que se inicie fazendo uma apresentação geral do assunto, após seja ressaltada a justificativa sobre a escolha do tema, os objetivos que se pretendem alcançar também devem ser especificados, explicitando a metodologia adotada para atingi-los.

Por último devem ser feitas referências às principais partes do texto, apresentando uma abordagem generalizada dos conteúdos dos capítulos e subcapítulos. 


\section{Revisão bibliográfica}

A revisão bibliográfica foi produzida anteriormente, assim basta inclui-la no relatório.

\section{Metodologia}

A metodologia também já foi produzida no plano de pesquisa, basta incluila no relatório.

\section{Resultados}

Os resultados serão incluídos no relatório, assim como a revisão bibliográfica e a metodologia.

\section{Conclusão (ou considerações finais)}

Na conclusão deve-se retornar ao problema de investigação, apresentando de forma sintetizada os resultados obtidos na investigação. Também se deve buscar explicitar se os objetivos foram atingidos, se a(s) hipótese(s) de investigação foi(ram) ou não confirmada(s), esclarecendo as razões desse resultado. Por fim, é importante que sejam ressaltadas as contribuições, econômica, social ou cultural trazidas pela realização do projeto investigativo, sugerindo novas abordagens a serem consideradas em trabalhos realizados futuramente.

\section{Referências}

Referências é a relação de obras e documentos citados no texto: teses, artigos, relatórios, livros, internet, etc. Devem ser apresentadas de acordo com as normas vigentes da ABNT NBR 6023.

As referências devem ser reunidas em lista ordenada alfabeticamente. 


\section{Apêndices (opcional)}

Apêndices referem-se a elementos elaborados pelo próprio autor, caso nenhum elemento foi elaborado, este elemento é dispensado.

Utilizam-se como apêndices gráficos, tabelas, figuras, além de fotografias, fluxogramas, cálculos, esquemas de experiências, quando, por sua dimensão e forma de apresentação, não podem ser incluídos no corpo do relatório; modelos de formulários e/ou impressos citados no texto, enfim, contribuições que servem para documentar, esclarecer, provar, confirmar ou complementar as ideias apresentadas no texto e que são importantes para sua perfeita compreensão.

Os apêndices devem ser identificados de acordo com a sequência da citação no desenvolvimento e titulados. É indispensável a referência aos apêndices no desenvolvimento das atividades para que eles não fiquem "soltos" e para que o leitor localize-os devidamente e compreenda melhor o que é relatado.

\section{Anexos (opcional)}

Assim como os apêndices, os anexos também são formados por gráficos, tabelas, figuras, etc. A única diferença é que os apêndices referem-se a elementos elaborados pelo próprio autor, já os anexos trazem elementos não elaborados pelo autor, ou seja, foram extraídos de uma fonte.

\section{Algumas sugestões para formatação:}

»O texto seja impresso em papel branco, formato A4.

» As folhas devem apresentar margens esquerda e superior de $3 \mathrm{~cm}$; direita e inferior de $2 \mathrm{~cm}$.

» Para digitação, seja utilizada a fonte Times New Roman de tamanho 12 para o texto e tamanho 10 para citações longas e notas de rodapé.

»O corpo do texto deve ser digitado com espaçamento 1,5 de entrelinhas; já as citações longas, as notas de rodapé, as referências e o resumo devem ser digitados em espaço simples.

»As folhas iniciais do trabalho, a partir da folha de rosto, devem ser contadas sequencialmente, mas não numeradas. A numeração é colocada, a partir da primeira folha da parte textual, em algarismos arábicos, no canto superior direito da folha. 


\section{Sobre os autores}

\section{Aline Fernanda Bileski}

Graduada em Licenciatura em Ciências da Natureza com Habilitação em Física pelo Instituto Federal de Ciência, Educação e Tecnologia de Santa Catarina (2016), mestra em Ensino de Ciências, Matemática e Tecnologias pela Universidade do Estado de Santa Catarina (2018). Atua no ensino de Física no Ensino Médio e Superior, com pesquisas na área de ensino-aprendizagem e formação de professores.

\section{Tatiana Comiotto}

Graduada em Pedagogia pela Universidade de Caxias do Sul (1986) e em Psicologia pela Associação Catarinense de Ensino (2014), mestra em Educação pela Pontifícia Universidade Católica do Rio Grande do Sul (1991) e doutora em Educação Científica e Tecnológica pela Universidade Federal de Santa Catarina (2008). Professora associada da Universidade do Estado de Santa Catarina. Tem experiência na área de educação, com ênfase em psicologia da educação. Atua no Programa de Pós-Graduação em Ensino de Ciências, Matemática e Tecnologias, com pesquisas na área de ensino-aprendizagem e formação de professores.

\section{Jaison Vieira da Maia}

Graduado em Licenciatura Plena em Física pela Universidade do Estado de Santa Catarina (2006), mestre em Ciência e Engenharia de Materiais pela Universidade do Estado de Santa Catarina (2009) e doutor em Engenharia Aeronáutica e Mecânica pelo Instituto Tecnológico de Aeronáutica (2014). Professor associado do Instituto Federal de Ciência, Educação e Tecnologia de Santa Catarina. Atua no Ensino Médio e Superior, com pesquisas na área de ensino-aprendizagem, formação de professores e aplicação de plasmas. 
Este livro foi editorado com as fontes Minion Pro e Raleway. Publicado on-line em: editora.ufsc.br/estante-aberta 

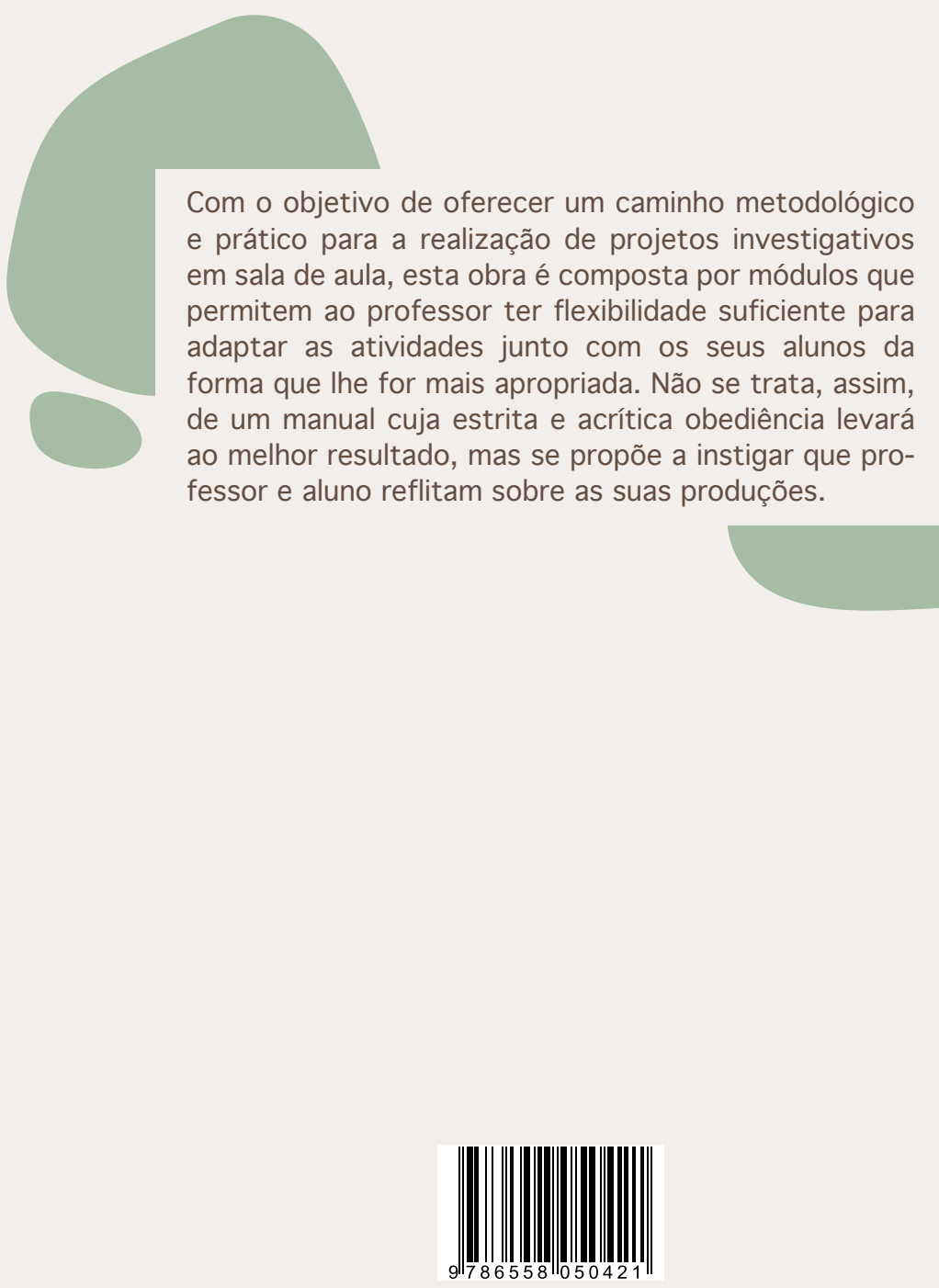